$\mathbf{E}^{\mathrm{n}}$ una ex cu rsión realizada a los bosques del Cerro Atesquillo, localizado en la Delegación Álva ro Obregón, Distrito Federal, México, llamó la atención un helecho de hojas muy grandes, de aproximadamente $2.5 \mathrm{~m}$ de largo, con prefoliación circinada de $40 \mathrm{~cm}$ de alto, muy escamosa, el cual fue reconocido como un taxón del género Phanerophlebia C.Presl. Al realizar la determinación del espécimen, éste correspondió a Phanerophlebia macrosora (Baker) Underw., familia Dryopteridaceae.

El hallazgo de esta especie tuvo lugar en una cañada húmeda y sombreada, en suelo de ori gen volcánico, en un bosque de encino perturbado localizado en la parte media del Ce rro Atesquillo. Éste se ubica en el pa raje La Coyotera, en el km 24.5 de la Calzada al Desierto de los Leones, en las afueras del poblado de San Bartolo Ameyalco, con coordenadas 19¹7'39' N, 99¹4'43" O, a una altitud de 2,800 m s.n.m. El material recolectado (número de colecta, $\mathrm{R}$. Valdez A.-1, 15 abril 2006) está depositado en el Herbario Metropolitano "Ramón Riba y Nava Esparza" (UAMIZ) de la Universidad Autónoma Metropolitana-Iztapalapa.

Dicha especie estaba registrada para los estados de Chiapas, Guerrero, Hidalgo, Jalisco, México (reportado sólo para el Mpio. Ocuilán), Michoacán, Oaxaca y Veracruz (Yatskiev y ch y Riba, 1999; Mickel y Smith, 2004; Tejero-Diez y Ameguín-Sánchez, 2004). Generalmente crece a altitudes entre $1,550 \mathrm{y}$ 3,200 m s.n.m., en suelos húmedos de cañadas y taludes sombreados, en bosque de pino-encino, bosque mesófilo de montaña, bosque tropical perennifolio y raramente en bosque de Quercus. Cabe señalar que

\title{
PHANEROPHLEBIA MACROSORA (BAKER) UNDERW. (DRYOPTERIDACEAE), REGISTRO NUEVO PARA EL Distrito Federal (MÉXICO)
}

\author{
Ricardo ValdeZ-Avila ${ }^{1}$, Aniceto MendoZA-Ruiz y BlancA \\ PÉREZ-García
}

Universidad Autónoma Metropolitana-Iztapalapa, Departamento de Biología, Área de Botánica Estructural y Sistemática Vegetal, Av. San Rafael Atlixco 186, Col. Vicentina, Del. Iztapalapa, México 09340, D.F., México.

'Autor para la correspondencia. Tel. (55) 58046458. Correo-e: ricardovaldeza@hotmail.com

esta especie no es muy abundante en las zonas donde crece, a diferencia de Phanerophlebia nobilis (Schltdl. et Cham.) C.Presl, especie de amplia distribución y muy abundante en los sitios donde se presenta (Moran y Riba, 1995; Mickel y Smith, 2004; Tejero-Díez y Arreguín-Sánchez, 2004).

Este nuevo registro de Phanerophlebia macrosora para el Distrito Federal amplía su área conocida de distribución geográfica y constituye una adición a las 113 especies de pteridofitas reportadas en la Flora del Valle de México (Arreguín-Sánchez et al., 2004).

De acuerdo con nuestras observaciones, Phanerophlebia macrosora se caracteriza por ser un helecho cuyas hojas, cuando están frescas, p resentan un olor a zorrillo fuerte y des agradable. Posee un rizoma ere cto o ascendente, cubiento por escamas de 10-15 mm de largo por 5-7 $\mathrm{mm}$ de ancho, ovadas a lanceoladoovadas, pardas con una área central lige ramente oscurecida; sus hojas miden de 70 a $250 \mathrm{~cm}$ de largo, con 6-17 pares de pinnas (figuras 1 y 3); las pinnas tienen hasta $27 \mathrm{~cm}$ de largo, son angostamente oblongolanceoladas, con la base oblicuamente cuneada a redondeada, los má rgenes son espinuloso-sernulados casi hasta la base y el ápice es atenuado (figura 4).

Las plantas de esta especie tienen el pecíolo más corto que la lámina o casi tan largo como ésta; las escamas del pecíolo son persistentes, densas y traslapadas, similares a las del rizoma (figura 2), las más anchas miden $7 \mathrm{~mm}$; las nervaduras son libres a 3-4 bifurcadas; los soros se disponen de 2 a 4 series entre la costa y el margen y son indusiados, el indusio mide 0.6-1.1 mm de diámetro y se contrae en la madure $z$ (figura 4); las esporas son monoletes, miden en promedio $35 \mu \mathrm{m}$ de an cho $\times 50 \mu \mathrm{m}$ de largo y el número cromosómico es $2 n=82$. Estas características de la especie coinciden y se complementan con las descripciones hechas por Mickel y

Valdez-Avila R, Mendoza-Ruiz A, Pérez-García B. 2007. Phanerophlebia macrosora (Baker) Underw. (Dryopteridaceae), registro nuevo para el Distrito Federal (México). Boletín de la Sociedad Botánica de México 80: 105-107. 

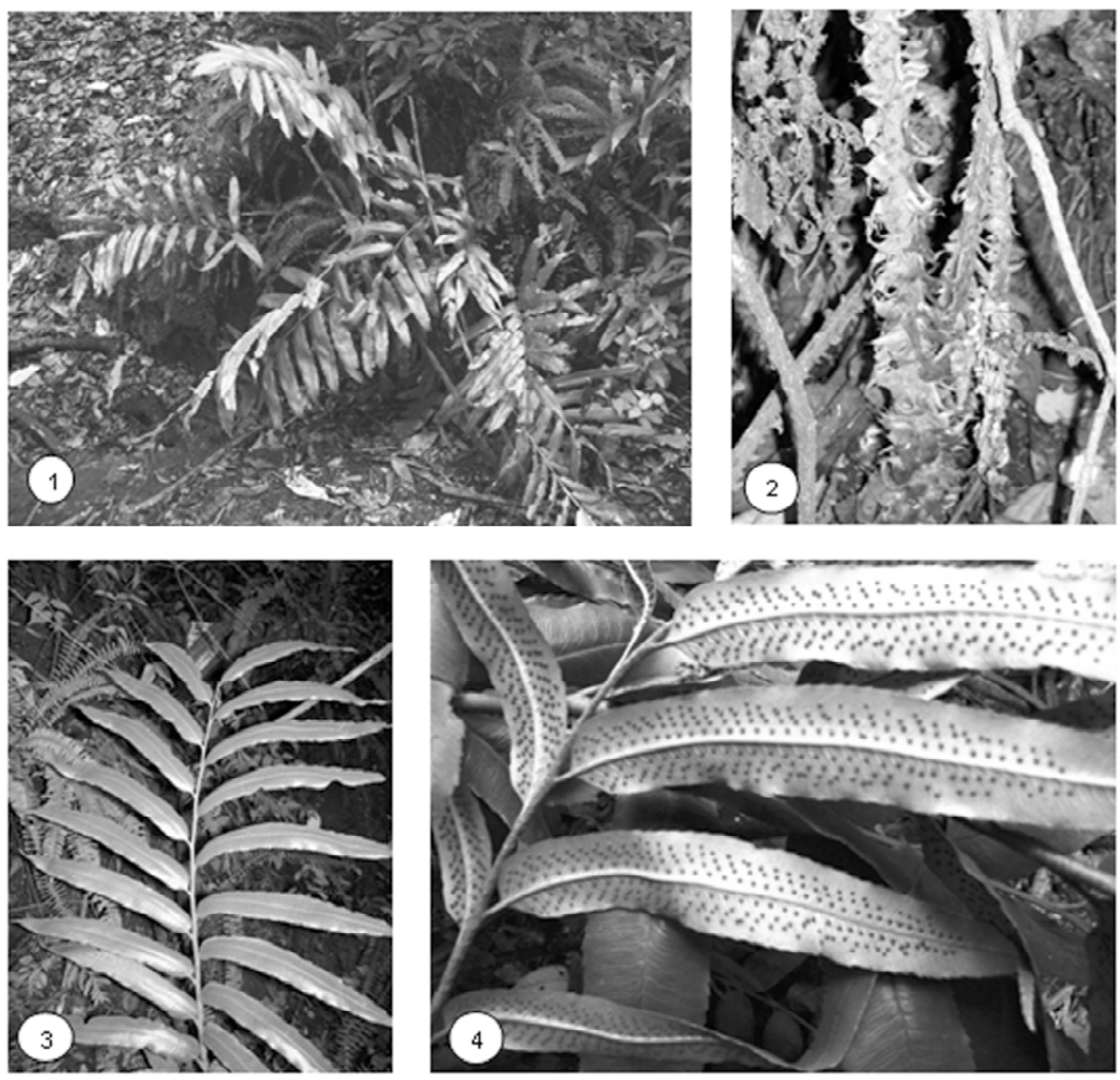

Figuras 1-4. 1. Phanerophlebia macrosora, planta completa creciendo en su hábitat. 2. Acercamiento del pecíolo, mostrando escamas persistentes, densas y traslapadas. 3. Detalle de la cara adaxial de la lámina. 4. Acercamiento de la cara abaxial de las pinnas con soros.

Smith (2004) y Moran y Riba (1995).

Hay pocas dudas de que el taxón registrado en esta área constituye una población silvestre y rara, con alrededor de 50 individuos, la mayoría de ellos fértiles, de las cuales sólo se recolectaron dos hojas sin rizoma con el fin de minimizar el daño a la población, la cual se encuentra restringida a la cañada, en luga res somb reados y suelos húmedos derivados de roca volcánica. Phanerophlebia macrosora fo rma parte de la composición vegetal natural de esta zona, pero el sitio donde se encuentra esta especie está amenazado por la creciente expansión urbana, pues dicha población se localizada a un $1 \mathrm{~km}$ de la mancha urbana de la ciudad de México. Aunado a esto, la tala inmode rada de árboles y el sobrepastoreo por ganado vacuno y bovino (gan adería extensiva), cu yos indicios son evidentes en el campo, pone en riesgo la desap a rición de ésta y muchas plantas más que crecen en la zona. Por tal razón, apelamos a las autoridades correspondientes a que tomen las medidas necesarias para evitar el crecimiento de los asentamientos humanos y a que se haga un esfuerzo por pro t eger el área. Quizá de esta manera se podría preservar la poca vegetación del sitio, donde crece un gran número de especies vegetales y donde otros organismos encuentra refugio.

\section{Agradecimientos}

Los autores agradecen a Ana Rosa López-Ferrari, Klaus Mehltreter, Jorge A. Meave y a un revisor anónimo, por sus comentarios y suge re n- 
cias para enriquecer el manu scrito, y a Luis Antonio Galicia Bamientos por su ap oyo incondicional en el trabajo de campo.

\section{Lite rat u ra citada}

Arreguín-Sánchez L.M., FernándezNava R. y Quiroz-Garáa D.L. 2004.

Pteridoflora del Valle de México.

Escuela Nacional de Ciencias

Recibido: 9 de febrero de 2007

Versión corregida: 9 de mayo de 2007

Aceptado: 9 de mayo de 2007
Biológicas, Instituto Politécnico Nacional, México, D.F.

Mickel J.T. y Smith A.R. 2004. The pteridophytes of Mexico. Memoirs of the New York Botanical Garden 88:457458.

Moran C.R. y Riba R. 1995. Dryopteridaceae. En: Davidse G., Sousa S.M. y Knapp S. Eds. Psilotaceae a Salviniaceae. Flora Mesoamericana, Vol. 1, pp. 210-216, Unive rsidad Nacional Autónoma de
México, México, D.F

Tejero-Díez J.L. y Arreguín-Sánchez M.L. 2004. Lista con anotaciones de las pteridofitas del Estado de México, México. Acta Botanica Mexicana 69.1-82.

Yatskievych G. y Riba R. 1999. Pteridofitas: familia Dryopteridaceae. Phanerophlebia. Flora de México 6:26-38. 